\title{
Effect of nitric oxide inhalation on respiratory system resistance in chronic obstructive pulmonary disease
}

\author{
N. Roger, J.A. Barberà, R. Farré, A. Cobos, J. Roca, R. Rodriguez-Roisin
}

Effect of nitric oxide inhalation on respiratory system resistance in chronic obstructive pulmonary disease. N. Roger, J.A. Barberà, R. Farré, A. Cobos, J. Roca, R. RodriguezRoisin. (C)ERS Journals Ltd 1996.

ABSTRACT: Nitric oxide (NO) has been identified as a neurotransmitter of nonadrenergic noncholinergic bronchodilator nerves. To investigate whether inhaled NO exerts a bronchodilator effect in patients with chronic obstructive pulmonary disease (COPD), we measured the resistance of the respiratory system, using the forced oscillation technique, while breathing NO.

Eight patients with COPD ( 7 men and 1 woman; aged $66 \pm 7$ yrs (mean \pm SD); forced expiratory volume in one second (FEV1) $37 \pm 17 \%$ of predicted) and eight healthy subjects ( 7 men and 1 woman; $33 \pm 4$ yrs; FEV1 108 $\pm 14 \%$ pred) were studied. Nitric oxide, at a concentration of $\mathbf{4 0}$ parts per million (ppm) in air, was inhaled for 20 min. Total resistance $(R \mathrm{rs})$ and reactance $\left(X_{\mathrm{rs}}\right)$ of the respiratory system, arterial oxygen saturation, heart rate, tidal volume, and breathing frequency were continuously recorded at baseline, and during and after ceasing NO inhalation. Methaemoglobin levels were additionally measured in healthy subjects.

At baseline, patients with COPD showed higher $R$ rs than healthy subjects (Rrs at $10 \mathrm{~Hz}(R r s, 10) 4.97 \pm 2.19$ vs $\left.2.29 \pm 0.65 \mathrm{hPa} \cdot \mathrm{L}^{-1} \cdot \mathrm{s}\right)$. During NO inhalation, no significant change in $R \mathrm{rs}$ or in $X \mathrm{rs}$ was observed. Mean variation in $R \mathrm{rs}, 10$ while breathing NO was negligible and similar in the two groups $\left(-0.10 \pm 0.13 \mathrm{hPa} \cdot \mathrm{L}^{-1} \cdot \mathrm{s}\right.$ in COPD patients and $-0.02 \pm 0.13 \mathrm{hPa} \cdot \mathrm{L}^{-1} \cdot \mathrm{s}$ in healthy subjects). Moreover, there were no differences in oxygen saturation, heart rate, tidal volume and breathing frequency during NO inhalation. Methaemoglobinaemia increased at the end of NO inhalation (from $0.48 \pm 0.18$ to $0.81 \pm 0.16 \%$ ), and this increment remained $10 \mathrm{~min}$ later $(0.86 \pm 0.31 \%)$.

From these results, we conclude that inhaled nitric oxide, at a concentration of $40 \mathrm{ppm}$, exerts no effect on respiratory system resistance in patients with chronic obstructive pulmonary disease or in healthy subjects.

Eur Respir J., 1996, 9, 190-195.

\begin{abstract}
Servei de Pneumologia i Al.lèrgia Respiratòria, Hospital Clínic, Departament de Medicina, Laboratori de Biofísica i Bioenginyeria, Facultat de Medicina, Universitat de Barcelona, and Unitat de Biometria, Departament de Recerca i Desenvolupament, QF Bayer SA, Barcelona, Spain.
\end{abstract}

\section{Correspondence: J.A. Barberà}

Servei de Pneumologia i Al.lèrgia Respiratoria

Hospital Clínic

Villarroel 170

08036 Barcelona

Spain

Keywords: Airway resistance chronic airflow obstruction forced oscillation technique lung impedance.

Received: March 11995

Accepted after revision November 271995

Supported by Grants FIS 94/1009, SEPAR/ 1992, FUCAP/1993, DGICYT PM92-0056 and CIRIT/GRQ 94-9103. NR is the recipient of a 1994 fellowship award from the Hospital Clínic of Barcelona.
Inhaled nitric oxide (NO) is a selective pulmonary vasodilator that can potentially improve pulmonary gas exchange in some patients with adult respiratory distress syndrome (ARDS) [1], and with chronic obstructive pulmonary disease (COPD) [2]. This improvement has been ascribed to the selective vasodilation of well-ventilated alveolar units, resulting in an amelioration of alveolar ventilation/perfusion $\left(V^{\prime} \mathrm{A} / Q^{\prime}\right)$ relationships [1]. Likewise, it has been suggested that inhaled NO might exert a bronchodilator effect in some individuals, hence improving alveolar ventilation and $V^{\prime} \mathrm{A} / Q^{\prime}$ relationships $[2,3]$.

Nitric oxide has been identified as an endogenous neurotransmitter of nonadrenergic noncholinergic (NANC) inhibitory nerves of human airways, with bronchodilator effect when assessed in vitro [4]. Experimental studies in guinea-pigs and rabbits have shown that inhaled NO modulates the increase in airway tone induced by methacholine [5, 6]. Similarly, NO inhalation may attenuate methacholine-induced bronchoconstriction in healthy individuals [7, 8], and exert a moderate bronchodilator effect in patients with bronchial asthma [7].

In patients with COPD, HöGMAN and co-workers [7] showed that the inhalation of 80 parts per million (ppm) of NO during 10 min exerted no effect on specific airway conductance ( $\mathrm{s} G \mathrm{aw}$ ), measured 10-20 s after terminating the NO inhalation. However, NO is a chemically unstable molecule with a very short half-life in aqueous media $(0.1-5 \mathrm{~s})$ because of its rapid oxidation to nitrite and nitrate [9], and it might be speculated that the lack of bronchodilator effect of NO could be due to its instantaneous loss of activity when returning the inspired concentration to baseline values. To overcome this potential limitation, we have used the forced oscillation technique, which allows the examination of the mechanical properties of the respiratory system by applying an external oscillation to the lung, and has the advantage that it can be used during normal breathing of room air or any other gas $[10,11]$. Accordingly, the present study was designed 
to investigate the effect of inhaled $\mathrm{NO}$ on the two components of respiratory system impedance, namely resistance $(R \mathrm{rs})$ and reactance $(X \mathrm{rs})$, that were measured simultaneously with NO inhalation by using the forced oscillation technique, in healthy subjects and patients with COPD.

\begin{abstract}
Methods
Subjects

The study was conducted in two groups of subjects: 1) eight patients with COPD with moderate to severe airflow obstruction (forced expiratory volume in one second (FEV1) $37 \pm 17 \%$ predicted, mean \pm SD); and 2) eight healthy volunteers with normal lung function (FEV1 $108 \pm 14 \%$ pred). Main anthropometric and lung function data are shown in table 1. Patients with COPD were stud-ied under stable clinical conditions. Inhaled shortacting bronchodilators and long-acting theophyllines were withdrawn 8 and $24 \mathrm{~h}$ before the study, respectively. The study was approved by the Research Committee on Human Investigations of Hospital Clínic and informed consent was obtained from each participant after the purpose of the study had been explained and understood.
\end{abstract}

\section{Procedures}

Forced spirometry before and after use of bronchodilator (300 $\mu \mathrm{g}$ of salbutamol) was performed the day before the study using a water-sealed spirometer (Biomedin, Milan, Italy). All but two COPD patients showed no significant bronchodilation with salbutamol. Mean values of forced spirometry and bronchodilator response are shown in table 1. Predicted values are those of our own laboratory [12].

Nitric oxide was delivered by means of a nonrebreathing circuit (fig. 1). Subjects breathed through a four sideports valve. The inspiratory port was connected by a unidirectional valve ("V" valve; W.E. Collins, Braintree, MA, USA) to a $30 \mathrm{~L}$ reservoir (W.E. Collins, Braintree, MA, USA). A manually-operated three-way valve (WE

Table 1. - Anthropometric and lung function data of healthy subjects and COPD patients

\begin{tabular}{lcc}
\hline & $\begin{array}{c}\text { Healthy } \\
(\mathrm{n}=8)\end{array}$ & $\begin{array}{c}\text { COPD } \\
(\mathrm{n}=8)\end{array}$ \\
\hline Age yrs & $33 \pm 4$ & $66 \pm 7$ \\
Gender M/F & $7 / 1$ & $7 / 1$ \\
FEV1 L & $4.46 \pm 0.82$ & $1.08 \pm 0.55$ \\
FEV1 \% pred & $108 \pm 14$ & $37 \pm 17$ \\
FVC \% pred & $100 \pm 13$ & $60 \pm 17$ \\
BR \% baseline & $3 \pm 3$ & $8 \pm 12$ \\
\hline
\end{tabular}

Values are presented as mean \pm SD. COPD: chronic obstructive pulmonary disease; M: male; F: female; FEV1: forced expiratory volume in one second; FVC: forced vital capacity; \% pred: percentage of predicted value; BR: bronchodilator response to $300 \mu \mathrm{g}$ salbutamol as \% change in FEV1.

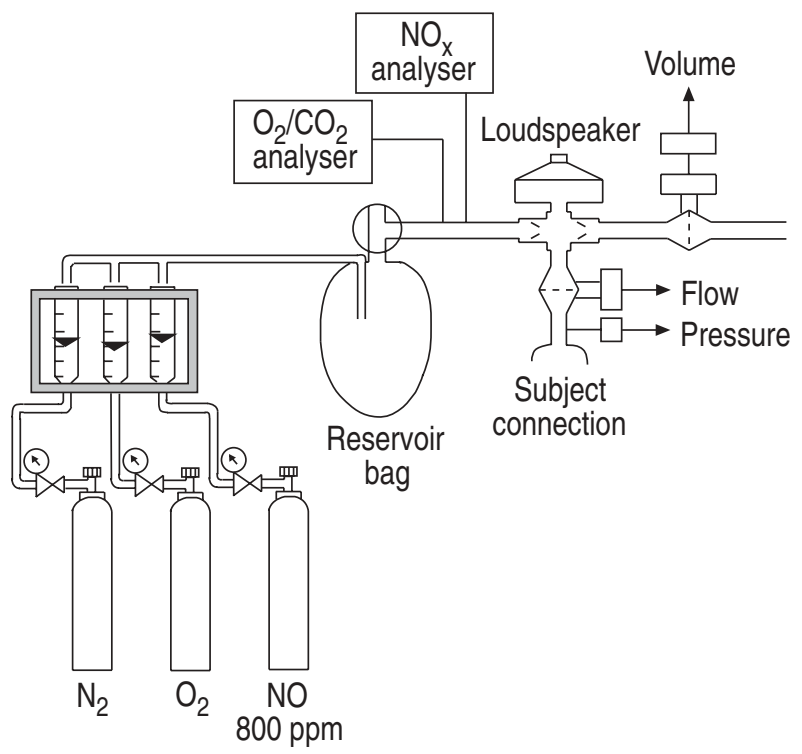

Fig. 1. - Closed nonrebreathing circuit for NO inhalation and measurement of respiratory system impedance.

Collins, Braintree, MA, USA) made it possible to connect the subject either to the NO breathing circuit or to room air. The inspired gas was a mixture of $\mathrm{O}_{2}, \mathrm{~N}_{2}$ and NO, obtained using a set of calibrated rotameters (Tecfluid SA, Barcelona, Spain). NO was obtained from a stock tank containing a mixture of 800 parts per million (ppm) of $\mathrm{NO}$ in $\mathrm{N}_{2}$ (Abelló, Barcelona, Spain). The estimated contact time of $\mathrm{NO}$ with $\mathrm{O}_{2}$ using this setting was approximately $3 \mathrm{~min}$. Inspired concentrations of $\mathrm{NO}$ and nitrogen dioxide $\left(\mathrm{NO}_{2}\right)$ were continuously monitored using a chemiluminescence analyser (model CLD 700AL; Eco Physics, Dürnten, Switzerland) at the inspiratory port. The mean concentration of NO that was actually inhaled was $38.5 \pm 1.8 \mathrm{ppm}$, and that of $\mathrm{NO}_{2}$ was $1.3 \pm 0.4 \mathrm{ppm}$. Inspired $\mathrm{O}_{2}$ concentration was also continuously controlled using a zirconium analyser (CPX System; Medical Graphics Corp., St. Paul, MN, USA) and adjusted at $21 \%$.

Total resistance and reactance of the respiratory system were measured using the forced oscillation technique, as described in detail previously $[11,13]$. The forced oscillations ( $2 \mathrm{hPa}$ peak-to-peak, 4-32 Hz) were generated by means of a loudspeaker enclosed in a chamber, servocontrolled [14] to withstand the pressure variation due to the subject's breathing, and applied at the mouth of the subject through the four-port valve (fig. 1). During the measurement, the subject wore a noseclip and supported her/his cheeks whilst breathing spontaneously. Flow at the mouth was measured with a mesh-wire screen pneumotachograph $\left(0.54 \mathrm{hPa} \cdot \mathrm{L}^{-1}\right)$ and an attached pressure transducer $( \pm 2 \mathrm{hPa}$, model LCVR; Celesco, Canoga Park, CA, USA). Pressure at the mouth was sensed with a piezoresistive transducer (model 174; Honeywell). Pressure and flow signals were filtered, sampled and processed as described previously [15]. Forced oscillation data were described by the mean value both of resistance $(\bar{R} \mathrm{rs})$ and reactance $\left(\bar{X}_{\mathrm{rs}}\right)$ over the whole frequency band explored $(6-30 \mathrm{~Hz})$, and also by the resistance at 
oscillation frequency of 6-14 Hz $(R \mathrm{rs}, 10)$. The latter parameter was used because in patients with COPD lung resistance shows a negative relationship with oscillation frequency [16].

Arterial oxygen saturation and heart rate were recorded using a pulse oximeter (Criticare CSI 504; Wankesha, WI, USA). Expiratory flow was continuously measured using a calibrated Fleisch pneumotachometer (E. Jaeger, Würzburg, Germany), and tidal volume was derived from the electrical integration of the flow signal and a differential pressure transducer $\left(\mathrm{MP} 45 \pm 2 \mathrm{cmH}_{2} \mathrm{O}\right.$; Validyne Corp., Northridge, CA, USA). Both haemoglobin and methaemoglobin were measured by light absorption using a CO-oximeter (Model 482; Instrumentation Laboratories, Milan, Italy) in blood samples collected through a polyethylene catheter inserted into a peripheral vein.

\section{Study protocol}

Initially, subjects breathed room air for $10 \mathrm{~min}$. Subsequently, they were connected to the NO delivery system and breathed $\mathrm{NO}$ at a concentration of $40 \mathrm{ppm}$ in air over a period of $20 \mathrm{~min}$. After this, the inspiratory circuit was switched to room air again for an additional 10 min. During the study, $R$ rs and $X$ rs were measured by forced oscillation at 1-3 min intervals. Overall, more than 25 measurements were performed in each subject. Arterial oxygen saturation $\left(\mathrm{S}_{\mathrm{a}}, \mathrm{O}_{2}\right)$, heart rate, tidal volume and breathing frequency were continuously recorded. Inspired $\mathrm{NO}, \mathrm{NO}_{2}$ and $\mathrm{O}_{2}$ concentrations were also continuously monitored. In healthy volunteers, peripheral venous blood was sampled to measure methaemoglobin concentration at baseline, at the end of the NO breathing period, and $10 \mathrm{~min}$ after stopping it.

\section{Statistical analysis}

Data are expressed as mean $\pm \mathrm{SD}$. To assess the effect of NO inhalation on the different variables, individual plots of each variable against time were visually inspected. Since no specific pattern of change was observed, we averaged individual data at baseline, during NO inhalation, and after inhalation [17], and compared them using paired t-tests.
Because measurements at baseline in patients with COPD clearly differed from those of healthy subjects (unpaired t-test), the difference between baseline and NO inhalation was considered the most appropriate variable to assess the effect of NO on the two populations, comparisons being performed by unpaired t-tests.

To further analyse the effect of NO on $R \mathrm{rs}, 10$, the major end-point variable, a linear regression model of the $R \mathrm{rs}, 10$ values during NO inhalation as a function of the baseline values and group was fitted. The $95 \%$ confidence interval of the regression coefficient was computed and used to assess the sensitivity of the test in detecting changes of $R \mathrm{rs}, 10$ during NO inhalation.

\section{Results}

At baseline, patients with COPD showed higher values of $R \mathrm{rs}, 10, \bar{R}$ rs and breathing frequency, and lower $\bar{X}_{\text {rs }}$ and $\mathrm{Sa}, \mathrm{O}_{2}$, than healthy subjects (table 2 ).

No specific pattern of response was shown in the individual time courses of $R \mathrm{rs}, 10$ throughout the study (fig. 2). Furthermore, no significant differences were shown between the average values at baseline, during NO inhalation, and thereafter (table 2). Mean change in Rrs,10 between baseline and NO inhalation in patients with COPD was $-0.10 \pm 0.36 \mathrm{hPa} \cdot \mathrm{L}^{-1} \cdot \mathrm{s}(-3.0 \pm 9.0 \%$ from baseline), and in healthy subjects was $-0.02 \pm 0.13 \mathrm{hPa} \cdot \mathrm{L}^{-1} \cdot \mathrm{s}$ $(-1.4 \pm 5.6 \%$ from baseline $)$. No difference in such change was shown between the two groups $(\mathrm{p}=0.54)$. Furthermore, the fitted linear model of the relationship between $R \mathrm{rs}, 10$ values at baseline with those observed during NO inhalation failed to detect any group effect. After removing this effect, the estimated regression parameter of this relationship was 1.02 , indicating no practical variation from the identity (fig. 3).

Values of $\bar{R}$ rs were analogous to those of $R \mathrm{rs}, 10$, and no differences were observed among the measurements performed in each condition (table 2). Furthermore, mean change in $\bar{R}$ rs during NO inhalation was similar in the two groups $\left(-0.07 \pm 0.28\right.$ and $0.01 \pm 0.14 \mathrm{hPa} \cdot \mathrm{L}^{-1} \cdot \mathrm{s}$, in COPD patients and healthy subjects, respectively; $p=0.67$ ). The evolution of $\bar{X}_{\text {rs }}$ was similar to that of $\bar{R}$ rs. At baseline, patients with COPD showed lower values of $\bar{X}$ ss than healthy subjects (table 2). Individual time courses of $\bar{X}$ rs throughout the study showed no specific change. Moreover,

Table 2. - Lung mechanics, cardiac and ventilatory responses to nitric oxide inhalation

\begin{tabular}{|c|c|c|c|c|c|c|}
\hline & \multicolumn{3}{|c|}{ Healthy subjects } & \multicolumn{3}{|c|}{ COPD } \\
\hline & Baseline & NO inhalation & Postinhalation & Baseline & NO inhalation & Postinhalation \\
\hline$R \mathrm{rs}, 10 \mathrm{hPa} \cdot \mathrm{L}^{-1} \cdot \mathrm{s}$ & $2.29 \pm 0.65$ & $2.27 \pm 0.72$ & $2.15 \pm 0.66$ & $4.97 \pm 2.19 *$ & $4.86 \pm 2.22$ & $4.88 \pm 2.32$ \\
\hline $\bar{R} \mathrm{rs} \quad \mathrm{hPa} \cdot \mathrm{L}^{-1} \cdot \mathrm{s}$ & $2.33 \pm 0.66$ & $2.34 \pm 0.75$ & $2.20 \pm 0.66$ & $4.19 \pm 1.76^{*}$ & $4.12 \pm 1.74$ & $4.13 \pm 1.86$ \\
\hline $\bar{X}_{\mathrm{rs}} \mathrm{hPa} \cdot \mathrm{L}^{-1} \cdot \mathrm{s}$ & $0.85 \pm 0.27$ & $0.95 \pm 0.36$ & $0.93 \pm 0.30$ & $-1.48 \pm 1.64 *$ & $-1.39 \pm 1.74$ & $-1.58 \pm 1.90$ \\
\hline $\mathrm{S}_{\mathrm{a}, \mathrm{O}_{2}} \%$ & $98 \pm 1$ & $97 \pm 1$ & $98 \pm 1$ & $92 \pm 5^{*}$ & $92 \pm 5$ & $92 \pm 5$ \\
\hline HR beats $\cdot \mathrm{min}^{-1}$ & $76 \pm 13$ & $77 \pm 13$ & $76 \pm 13$ & $89 \pm 9$ & $89 \pm 10$ & $88 \pm 10$ \\
\hline$V \mathrm{~T} \mathrm{~mL}$ & $614 \pm 149$ & $644 \pm 151$ & $674 \pm 144$ & $525 \pm 169$ & $515 \pm 94$ & $490 \pm 92$ \\
\hline$f \mathrm{R}$ breaths $\cdot \mathrm{min}^{-1}$ & $13 \pm 5$ & $13 \pm 5$ & $14 \pm 5$ & $19 \pm 2 *$ & $21 \pm 2$ & $22 \pm 2$ \\
\hline
\end{tabular}

Values are the average of continuously recorded measures in each period \pm SD. COPD: chronic obstructive pulmonary disease; $R \mathrm{rs}, 10$ : total respiratory resistance at $10 \mathrm{~Hz} ; \bar{R}_{\mathrm{rs}}$ : mean value of total respiratory resistance; $\bar{X}_{\mathrm{rs}}$ : mean value of total respiratory reactance; $\mathrm{Sa}_{\mathrm{a}} \mathrm{O}_{2}$ : arterial oxygen saturation; HR: heart rate; $V \mathrm{~T}$ : tidal volume; $f \mathrm{R}$ : breathing frequency. *: $\mathrm{p}<0.05$ compared with healthy subjects. 

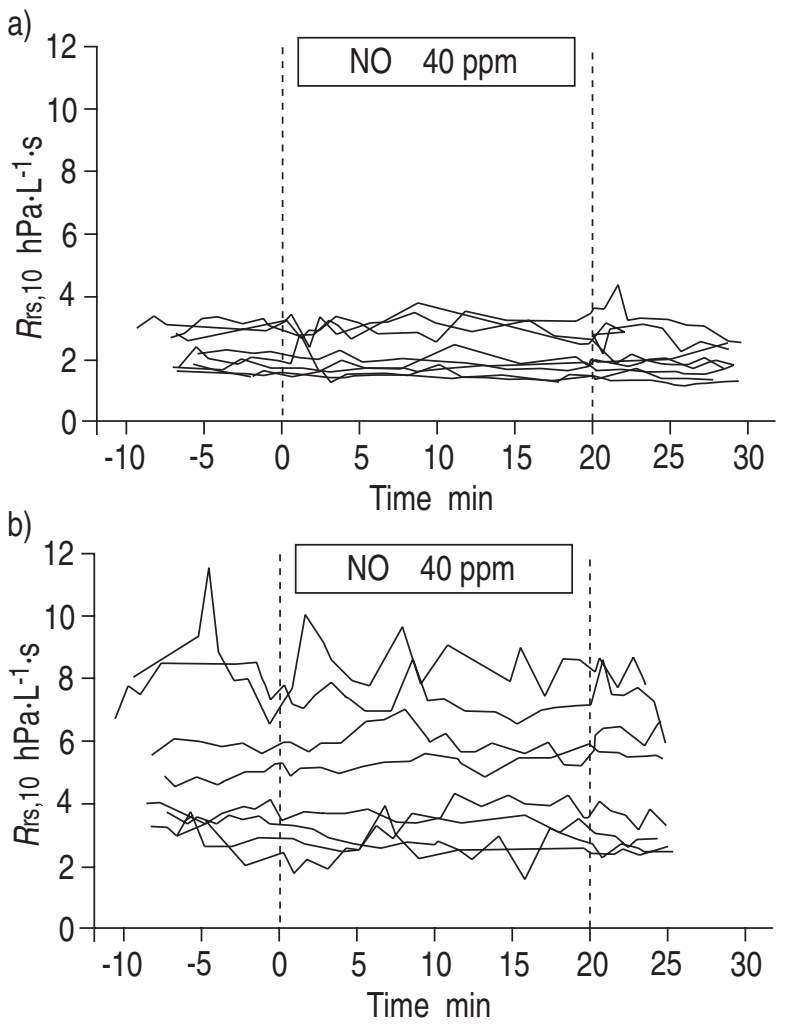

Fig. 2. - Individual time-courses of respiratory system resistance at $10 \mathrm{~Hz}(R \mathrm{rs}, 10)$ before, during and after NO inhalation: a) in healthy subjects; and b) in patients with COPD. The latter exhibited a greater individual variability. However, no specific change in $R \mathrm{rs}, 10$ was observed through the study in any subject of the two groups. COPD: chronic obstructive pulmonary disease.

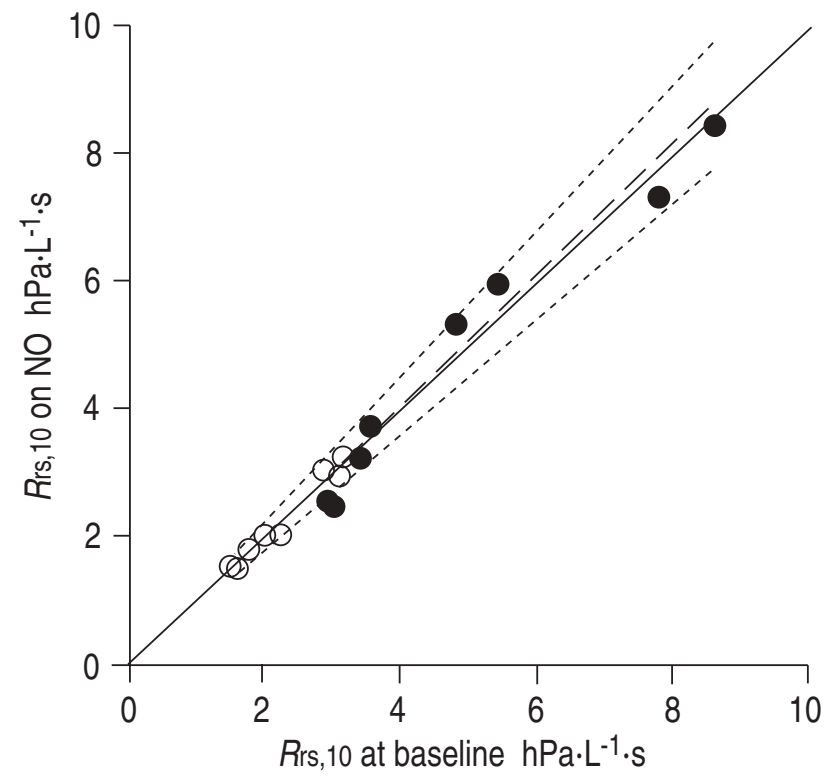

Fig. 3. - Plot of the individual values of respiratory system resistance at $10 \mathrm{~Hz}(R \mathrm{rs}, 10)$ at baseline against those observed during NO inhalation, in healthy subjects $(\bigcirc)$ and patients with COPD $(\bigcirc)$. The regression line $( \pm 95 \%$ confidence intervals) (dashed and dotted lines) and the identity relationship (continuous line) are shown. No systematic variation from the identity was observed, indicating that NO had no effect on $R_{\mathrm{rs}}, 10$, either at low or high values of baseline $R_{\mathrm{rs}, 10}$. COPD: chronic obstructive disease. no significant difference was observed between average values at baseline, during $\mathrm{NO}$ inhalation, and thereafter (table 2). Mean change in $X$ rs during NO inhalation was $0.09 \pm 0.27 \mathrm{hPa} \cdot \mathrm{L}^{-1} \cdot \mathrm{s}$ in patients with COPD, and $0.11 \pm 0.12$ $\mathrm{hPa} \cdot \mathrm{L}^{-1} \cdot \mathrm{s}$ in healthy subjects, such a difference being similar in the two groups $(\mathrm{p}=0.88)$.

Furthermore, no changes were found in $\mathrm{Sa}_{\mathrm{a}} \mathrm{O}_{2}$, heart rate, breathing frequency and tidal volume whilst breathing NO (table 2). Methaemoglobin levels measured in healthy subjects increased at the end of NO inhalation (from $0.48 \pm 0.18$ to $0.81 \pm 0.16 \%$; $\mathrm{p}<0.01$ ), and this increment persisted $10 \mathrm{~min}$ later $(0.86 \pm 0.31 \%$; $\mathrm{p}<0.05)$.

\section{Discussion}

The present study shows that the inhalation of NO, at a concentration of $40 \mathrm{ppm}$, has no effect on the resistance and reactance of the respiratory system in patients with COPD or in healthy subjects.

Our results are consistent with those of HöGMAN and co-workers [7], who found no significant changes in specific airway conductance ( $\mathrm{s} G$ aw), measured by body plethysmography after breathing NO at a concentration of 80 ppm for $10 \mathrm{~min}$, either in healthy subjects or in patients with COPD. By contrast, they found a weak but significant bronchodilator effect of NO in patients with bronchial asthma and in subjects with bronchial hyperreactivity after methacholine challenge [7]. In the asthmatics, $\mathrm{s} G$ aw increased from $0.4 \pm 0.1$ to $0.6 \pm 0.2 \mathrm{~s}^{-1} \cdot \mathrm{kPa}^{-1}$ after $80 \mathrm{ppm}$ NO inhalation. However, this change was much lower than that induced by a $\beta_{2}$-agonist inhalation. In the patients with bronchial hyperreactivity, there was a $45 \pm$ $16 \%$ decrease in the sGaw response to methacholine when the nebulization was performed simultaneously with 80 ppm NO [7]. The rationale behind the bronchodilator effect of NO is based on its action as a neurotransmitter of NANC bronchodilatory nerves [4]. However, according to the results of the present study and those of HöGMAN and co-workers [7], NO appears to exert no effect on bronchial tone in patients with fixed airflow obstruction, at concentrations both of 40 and $80 \mathrm{ppm}$. This is not surprising, since airflow obstruction in COPD is mostly produced by structural abnormalities of the airways and lung parenchyma, whilst the neural regulation of bronchial tone plays only a minor role [18].

It might be speculated that the potential bronchodilator effect of NO could have been neutralized by a bronchoconstrictor action of $\mathrm{NO}_{2}$, that was generated from the mixing of $\mathrm{NO}$ with $\mathrm{O}_{2}$. We think this was unlikely, since the inhalation of $\mathrm{NO}_{2}$ during short periods of time at concentrations up to $4 \mathrm{ppm}$ exerts no significant effect on lung function either in healthy subjects or in COPD patients [19].

The rate of disappearance of $\mathrm{NO}$ in exhaled air, after breathing it for a short period of time is very high [20]. GERLACH et al. [21] reported that the vascular effects of NO reversed 1 min after interruption of its inhalation, at doses in the parts per billion (ppb) range. By contrast, FROSTELL et al. [20] found the vasodilator effect of NO persisted $6 \mathrm{~min}$ after discontinuing its inhalation, at a 
concentration of $40 \mathrm{ppm}$. Since the time course of the potential bronchodilator effect of NO is unknown, our study was specifically designed to assess $R$ rs and $X$ rs during and not after NO inhalation by using the forced oscillation technique. This technique has the advantage that it can be applied during normal breathing of room air or other gases, and does not require co-operation from the subject to perform panting or special ventilatory manoeuvres, such as deep inspirations. No changes in $R$ rs or $\bar{X}_{\text {rs }}$ were identified throughout the study period, either in healthy subjects or in COPD patients (fig. 2). Accordingly, our results indicate that the lack of effect of NO on airway tone cannot be attributed to its wash-out from the airways.

It could be argued that the forced oscillation technique is not sensitive enough to detect moderate changes in airway resistance. We discard this possibility because, as has been recently reported, forced oscillation is among the most sensitive tests to detect reversibility of airway obstruction. VAN NOORD and co-workers [22] have shown that the inhalation of a small dose of salbutamol $(40 \mu \mathrm{g})$ induced a $21 \pm 17 \%$ decrease in $R$ rs measured by forced oscillation in patients with moderate airflow obstruction (FEV1 $57 \pm 24 \%$ pred). The percentage change in $R$ rs was lower than that of sGaw $(72 \pm 72 \%)$ but slightly greater than that of FEV1 $(19 \pm 16 \%)$. Furthermore, the same group of investigators [23], as well as DuIVERMAN et al. [24], have shown that measurements of $R$ rs at oscillation frequencies similar to those reported in the present study are among the most reliable and discriminative parameters to be used for the assessment of bronchial reactivity to histamine challenge. In our laboratory, we have previously reported significant changes in $R \mathrm{rs}$, measured by forced oscillation, following methacholine challenge in patients with mild bronchial asthma [25], and also after platelet-activating factor (PAF) inhalation both in healthy subjects [26] and patients with asthma [27]. Moreover, in our study the $95 \%$ confidence interval of the relationship between values of $R \mathrm{rs}, 10$ at baseline with those observed during NO inhalation ranged 0.91-1.14 (fig. 3), indicating that the uncertainty about the potential change in Rrs, 10 during NO inhalation was confined to a $-10 \%$ decrease up to a $+14 \%$ increase.

In our study, patients with COPD exhibited a greater intra-individual variability than healthy subjects (fig. 2). Nevertheless, the potential effect of such variability on the results was minimized by the multiple measurements that were performed in each subject breathing either room air or NO. The mean coefficient of variation of $R \mathrm{rs}, 10$ at baseline was $5.7 \pm 2.8 \%$ in healthy subjects and $10.7 \pm 7.4 \%$ in patients with COPD, values lower than those reported by VAN NOORD and co-workers [22] both for sGaw (14.9\%) and $\operatorname{Rrs}(15.2 \%)$ in patients with airflow obstruction.

The effects of inhaled NO on pulmonary circulation and gas exchange in humans have been reported using a wide range of concentrations, $0.06-80 \mathrm{ppm}[1-3,18$, 19]. The $40 \mathrm{ppm}$ concentration used in the present study was chosen because at this dose inhaled NO might improve gas exchange in COPD [2]. Our results indicate that at this concentration NO has no bronchodilator effect of clinical relevance. Therefore, despite the fact that inhaled NO can ameliorate pulmonary hypertension in COPD patients $[2,3]$, our results support the notion that the potential benefit of inhaled NO on gas exchange in these patients, if any, is likely to be related to a selective vasodilation of well-ventilated alveolar units [1], rather than to an increase of ventilation in alveolar units with low $V^{\prime} \mathrm{A} / Q^{\prime}$ ratio, as suggested previously [3]. Although the effects of NO on gas exchange were not specifically addressed in our present study, no changes were observed in arterial oxygen saturation measured by pulse oximetry. The latter, however, has a low sensitivity to detect minor changes in arterial oxygen tension $\left(\mathrm{Pa}_{\mathrm{a}} \mathrm{O}_{2}\right)$ [28].

The increase in methaemoglobin during and after NO inhalation indicates that NO had a good access to the alveolar space and that the inhaled dose of NO was sufficient to bind to haemoglobin to a significant level, even in the absence of an effect on airway resistance.

In summary, our study supports the view that inhaled $\mathrm{NO}$, at a concentration of $40 \mathrm{ppm}$, exerts no significant effect on respiratory system resistance and reactance in patients with COPD or in healthy subjects.

Acknowledgements: The authors thank the technical staff of the Pulmonary Function Laboratory for their cooperation, J. Cardús for his excellent assistance, and J. MilicEmili for helpful comments.

\section{References}

1. Rossaint R, Falke KJ, López F, Slama K, Pison U, Zapol WM. Inhaled nitric oxide for the adult respiratory distress syndrome. N Engl J Med 1993; 328: 399-405.

2. Adnot S, Kouyoumdjian C, Defouilloy C, et al. Hemodynamic and gas exchange responses to infusion of acetylcholine and inhalation of nitric oxide in patients with chronic obstructive lung disease and pulmonary hypertension. Am Rev Respir Dis 1993; 148: 310-316.

3. Moinard J, Manier G, Pillet O, Castaing Y. Effect of inhaled nitric oxide on hemodynamics and $\mathrm{V}_{\mathrm{A}} / \mathrm{Q}$ inequalities in patients with chronic obstructive pulmonary disease. Am J Respir Crit Care Med 1994; 149: 1482-1487.

4. Belvisi MG, Stretton CD, Yacoub M, Barnes PJ. Nitric oxide is the endogenous neurotransmitter of bronchodilator nerves in humans. Eur J Pharmacol 1992; 210: 221-222.

5. Dupuy PM, Shore SA, Drazen JM, Frostell C, Hill A, Zapol WM. Bronchodilator action of inhaled nitric oxide in guinea-pigs. J Clin Invest 1992; 90: 421-428.

6. Högman M, Frostell C, Arnberg H, Hedenstierna G. Inhalation of nitric oxide modulates methacholine-induced bronchoconstriction in the rabbit. Eur Respir J 1993; 6: 177-180.

7. Högman M, Frostell CG, Hedenström H, Hedenstierna G. Inhalation of nitric oxide modulates adult human bronchial tone. Am Rev Respir Dis 1993; 148: 1474-1478.

8. Sanna A, Kurtansky A, Veriter C, Stanescu D. Bronchodilator effect of inhaled nitric oxide in healthy men. Am J Respir Crit Care Med 1994; 150: 1702-1704.

9. Gaston B, Drazen JM, Loscalzo J, Stamler JS. The biology of nitrogen oxides in the airways. Am J Respir Crit Care Med 1994; 149: 538-551. 
10. Peslin R. Methods for measuring total respiratory impedance by forced oscillations. Bull Eur Physiopathol Respir 1986; 22: 621-631.

11. Farré R, Peslin R, Rotger M, Navajas D. Human lung impedance from spontaneous breathing frequencies to 32 Hz. J Appl Physiol 1994; 76: 1176-1183.

12. Roca J, Sanchis J, Agustí-Vidal A, et al. Spirometric reference values for a mediterranean population. Bull Eur Physiopathol Respir 1986; 22: 217-224.

13. Navajas D, Farré R, Rotger M, Milic-Emili J, Sanchis J. Effect of body posture on respiratory impedance. J Appl Physiol 1988; 64: 194-199.

14. Farré R, Ferrer M, Rotger M, Navajas D. Servocontrolled generator to measure respiratory impedance from 0.25 to $26 \mathrm{~Hz}$ in ventilated patients at different PEEP levels. Eur Respir J 1995; 8: 1222-1227.

15. Farré R, Rotger M, Navajas D. Optimized estimation of respiratory impedance by signal averaging in the time domain. J Appl Physiol 1992; 73: 1181-1189.

16. Clément J, Làndsér FJ, Van de Woestinje KP. Total resistance and reactance in patients with respiratory complaints and without airways obstruction. Chest 1983; 83: 215-220.

17. Matthews JNS, Altman DG, Campbell MJ, Royston P. Analysis of serial measurements in medical research. $\mathrm{Br}$ Med J 1990; 300: 230-235.

18. Barnes PJ. Neural control of human airways in health and disease. Am Rev Respir Dis 1986; 134: 1289-1314.

19. Gong H. Healthy effects of air pollution: a review of clinical studies. Clin Chest Med 1992; 13: 201-214.

20. Frostell CG, Blomqvist H, Hedenstierna G, Lundberg J, Zapol WM. Inhaled nitric oxide selectively reverses human hypoxic pulmonary vasoconstriction without causing systemic vasodilation. Anesthesiology 1993; 78: 427-435.

21. Gerlach H, Pappert D, Lewandowski K, Rossaint R, Falke KJ. Long-term inhalation with evaluated low doses of nitric oxide for selective improvement of oxygenation in patients with adult respiratory distress syndrome. Intensive Care Med 1993; 19: 443-449.

22. Van Noord JA, Smeets J, Clement J, Van De Woestijne KP, Demedts M. Assessment of reversibility of airflow obstruction. Am J Respir Crit Care Med 1994; 150: $551-554$

23. Van Noord JA, Clement J, Van de Woestijne KP, Demedts M. Total respiratory resistance and reactance as a measurement of response to bronchial challenge with histamine. Am Rev Respir Dis 1989; 139: 921-926.

24. Duiverman EJ, Neijens HJ, Van der Snee-van Smaalen M, Kerrebijn KF. Comparison of forced oscillometry and forced expirations for measuring dose-related responses to inhaled methacholine in asthmatic children. Bull Eur Physiopathol Respir 1986; 22: 433-436.

25. Rodriguez-Roisin R, Ferrer A, Navajas D, Agusti AGN, Wagner PD, Roca J. Ventilation-perfusion mismatch after methacholine challenge in patients with mild bronchial asthma. Am Rev Respir Dis 1991; 144: 88-94.

26. Rodriguez-Roisin R, Félez MA, Fan Chung K, et al. Platelet-activating factor causes ventilation-perfusion mismatch in humans. J Clin Invest 1994; 93: 188-194.

27. Félez MA, Roca J, Barberà JA, et al. Inhaled plateletactivating factor worsens gas exchange in mild asthma. Am J Respir Crit Care Med 1994; 150: 369-373.

28. Hannhart B, Haberer JP, Saunier C, Laxenaire MC. Accuracy and precision of fourteen pulse oximeters. Eur Respir J 1991; 4: 115-119. 